\title{
Using Actor-Network Theory to Understanding Virtual Community Networks of Older People Using the Internet
}

\author{
Jerzy Lepa and Arthur Tatnall \\ Victoria University, Australia
}

\begin{abstract}
Older people around the world are adopting the Internet at an increasing rate, and in the process are forming virtual community networks in a way that would not otherwise have been possible. Internet interactions by this group include e-mail, chat groups, community forums and discussion groups as well as the individual use of the Web for information purposes. Some of these virtual networks relate older people to other older people, while other networks span age groups as when, for instance, a grandmother communicates by e-mail with her grandchildren. But linking to the Internet is not always straightforward as family members, friends and the technology, along with other non-human actors, often intrude. This highlights the socio-technical nature of these networks and the need to investigate them in a way that allows this to be seen. To attempt an understanding of the formation and operation of virtual networks of older people, and the interactions involved, a socio-technical approach is required and this paper will attempt such an analysis based on research, in an Australian context, undertaken by the authors.
\end{abstract}

\section{Introduction}

Worldwide the proportion of older people is growing. Increasingly this group is accessing the World Wide Web for a variety of purposes including e-mail, finance, health and genealogy. Many use the Web as a means of reducing their social isolation (Swindell 2002), even though there is some evidence to suggest that social isolation may increase with the reduction of face-to-face contact with family and friends. The term 'virtual community of older people' is a very broad term describing the group of older people who access the Web. The literature reveals different interpretations of this term and also different types or classifications of virtual communities.

There are several different definitions of what constitutes an 'older person' but for the purposes of this paper we will define older people as those of sixty-five years of age and over, no longer in the full-time

Copyright (C) 2006 Victoria University. This document has been published as part of the Journal of Business Systems, Governance and Ethics in both online and print formats. Educational and non-profit institutions are granted a nonexclusive licence to utilise this document in whole or in part for personal or classroom use without fee, provided that correct attribution and citation are made and this copyright statement is reproduced. Any other usage is prohibited without the express permission of the workforce. The proportion of older people in Australia will increase dramatically over the next 25 years. Foskey (1998) notes that since the $19^{\text {th }}$ century there has been a 'longevity revolution' in the Western world and that in Australia during the past decade, the over sixty-five age group, living in nonmetropolitan areas, has seen the greatest rate of growth. 
Figures from the Australian Bureau of Statistics (ABS) indicate that older people are taking up Internet technology at a rapid rate, but that their use of the Internet for electronic commerce (e-commerce) activities remains quite low, with older people forming just $1 \%$ of the total of adult Internet shoppers (Australian Bureau of Statistics 2000). The ABS defines older people, for statistical purposes, as those who are fifty-five years of age and over.) Individual older people often have particular needs that differ from those of younger people, and it appears that use of the Internet may help with some of these. As people grow older they can become physically less mobile and could benefit if they were able to conduct more of their financial affairs, such as banking and bill paying, from home. In other words, e-commerce has something useful to offer them. The research literature (Williamson, Bow and Wale 1996; Council on the Ageing 2000; Mitchell 2000; Lloyd 2001), however, and also data from an Older Person Focus Group in Melbourne (Council on the Ageing 2000), reveals significant barriers to the adoption of ecommerce by older people.

This paper investigates older people's use of the GreyPath portal, a site designed to appeal to the interests of older Australians, but open to everyone. We argue that those older people making use of the portal constitute a virtual community (Lepa and Tatnall 2002; Lepa and Tatnall 2004).
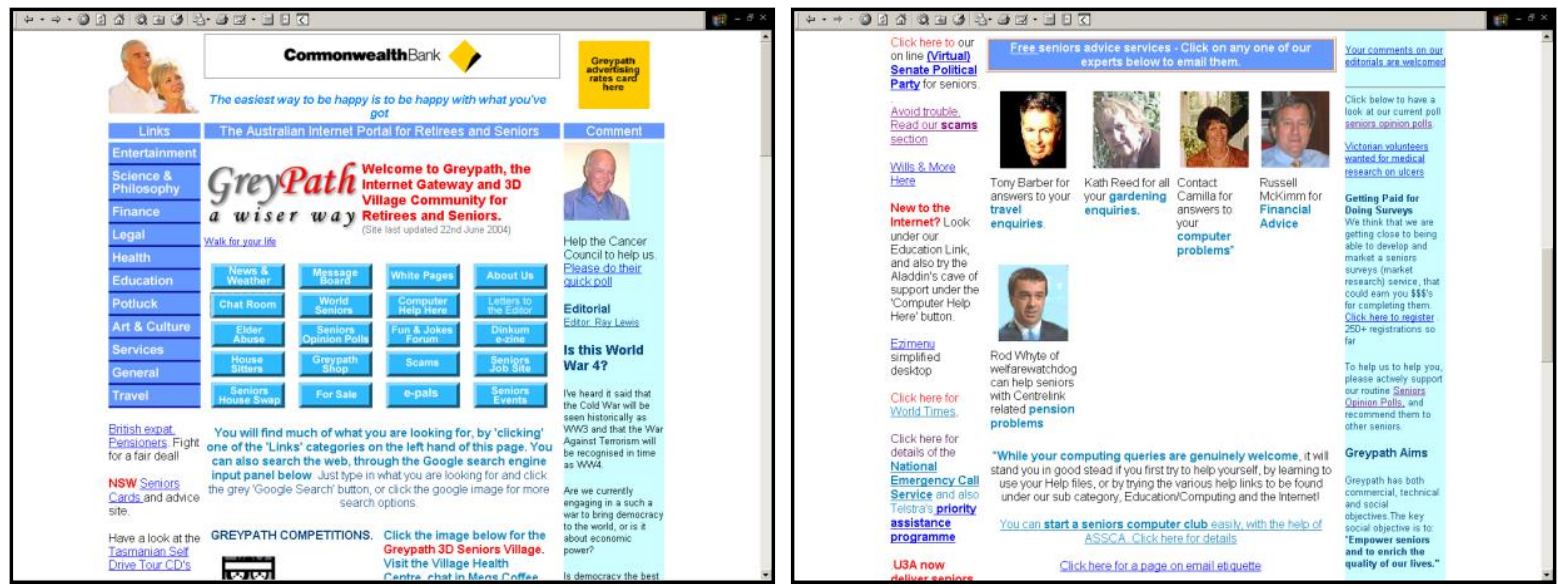

Figure 1: The GreyPath Portal - home page

\section{Virtual Communities and the Internet}

The Collins English Dictionary (1992) defines a community as "a group of people having cultural, religious, ethnic or other characteristics in common." A virtual community is a group of people who share a common interest or bond, but rather than meeting physically they "form communities that cross geographical, social, cultural and economic boundaries" (Matathia 1998:156) and communicate via the Internet (Matathia 1998; Schneider and Perry 2001:10). Rheingold (1993:5) defines virtual communities as "social aggregations that emerge from the Net where enough people carry on those public discussions long enough, with sufficient human feeling, to form webs of personal relationships in cyberspace". Examples of virtual communities on the Internet include music lovers with an affection for a particular genre, teenagers battling through 'the trials and tribulations of adolescence', and the group of older people who share a common life stage (Matathia 1998).

There are a number of alternative names for virtual communities such as 'communities of interest' (Hagel and Armstrong 1997) and 'Internet cultures' (Jones 1995). From an on-line marketing perspective Muniz (1997) calls them 'brand communities' and Kozinets (1998) uses the term 'virtual communities of consumption'. Barnatt (1998) suggests that there are two categories of virtual community: off-line and on-line. Both categories share common interests and bonds but on-line, Internet-based virtual communities today "allow a wide range of global individuals to argue, share information, make friends, and undertake economic exchanges, in a flexible and socially-compelling common on-line arena" (Barnatt 1998). In contrast, members of an off-line virtual community do not 
communicate directly with one another but are reliant on 'broadcast' mediums such as newschapters, $\mathrm{TV}$ and radio to sustain their common interests or bonds.

The group of Australian older people who use the Web share the common bond of ageing (Bosler 2001) and can be considered to form an on-line virtual community. Matathia (1998) suggests that these on-line relationships can be every bit as strong and permanent as their 'real world' counterparts. Individuals in this group, prior to accessing the Internet, would have been classified as part of the off-line community of older Australian people.

The term 'online community' has various interpretations. Armstrong and Hagel (2000) refer to online communities as 'electronic communities', while Jones (1997) calls then 'virtual settlements'. Rheingold (1998), an early pioneer, states that "Virtual communities exist and play a socialisation role to the same extent as 'real' communities do". Barnatt (1998) suggests that "although a 'virtualised' community is "not there" in the same sense that a geographically based community is assumed to be, it is still guided by passions and projects, conflicts and relationships". Other authors, Henri and Pudelko (2003) note, do not support the concept of virtual communities. "... since for them the concept of community cannot be dissociated from a common physical space and from a history shared by its members, two elements on which complex social relationships are based." Jones (1997) suggests that a 'virtual settlement' has four major features:

1. a minimum level of conversation between communicators;

2. at least two communicators must participate;

3. the 'virtual settlement', can be a single or group of Web sites that should be readily identified as a place in cyberspace. Hamman (2003) calls this an 'online third place' which can take the form of chat rooms, chat groups, lists, electronic mail, and conferencing systems;

4. the "virtual settlement' should feature a "sustained, long-term membership".

An online community, Preece (2000) suggests, should consists of:

1. "people, who interact socially as they strive to satisfy their own needs or perform special roles, such as leading or moderating;

2. a shared purpose, such as an interest, need, information exchange, or service that provides a reason for the community;

3. policies, in the form of tacit assumptions, rituals, protocols, rules and laws that guide people's interactions;

4. computer systems, to support and mediate social interaction and facilitate a sense of togetherness."

There are several types or classifications of virtual community including that proposed by Henri and Pudelko (2003) based upon Wenger's social learning theory. For this paper, however, we have chosen the classification proposed by Armstrong and Hagel (2000):

- Communities of transaction: involves the buying and selling of goods and services and members are encouraged to interact with one another by interchanging information about these goods and services. An example is www.wine.com - a virtual vineyard, but this site does not allow for visitors to trade information with each other.

- Communities of interest: members interact extensively on a specific topic area. Garden Web, www.gardenweb.com is a site where visitors can share ideas with others.

- Communities of fantasy: "participants create new personalities or personas for themselves and act out roles as in improvisational theatre". Participants, through the use of chat, can act out their fantasies by assuming the persona of someone like Superman or Batman.

- Communities of relationship: "sharing of intensely personal experiences generally while masking identities". These include groups of people focused on cancer care, divorce, widowhood or infertility. 
Armstrong and Hagel's (2000) classification of 'electronic communities' and the definition of virtual community from Preece (2000) have been used to investigate the GreyPath portal. Communities of interest such as the group of older person book lovers and art lovers are established when accessing the chat facilities and message boards available through the GreyPath Village and also the main GreyPath site. Visitors to these areas of the GreyPath portal can interact socially and anonymously about their specific interests of books or art. It is possible for many virtual communities to exist at any one time and also the same people can belong to many different virtual communities concurrently. The GreyPath chat rooms and message boards facilitate all of this. A visit to the chat rooms at GreyPath did not show any evidence to support the existence of communities of fantasy or communities of relationship. The GreyPath portal does not support community of transactions as there is no buying and selling of goods or information exchanged between potential customers.

\section{Older People and Their Needs}

The US-based Spry Foundation (2000) sees the needs of older people revolving around four interrelated themes:

- financial security,

- physical health and well being,

- mental health and social environment, and

- engaging in intellectual endeavours.

Older people have many needs, and a recent study in the United States showed a wide range of responses in terms of the concerns of older people (Wenger 1997). The study did reveal, however, that health (physical and mental) and mobility concerns were paramount and showed a larger degree of consensus across the sample. Financial security is seen as particularly important by older people who, in retirement, need to be assured of adequate income to maintain their lifestyle. Many older people in Australia, as well as in Europe and North America, must arrange their own retirement finances and in doing so seek appropriate investment information (Cutler 1997; Manchester 1997).

The Australian Federal Government has released a number of issues papers that are related to older people's capacity to remain active and independent (Bishop 2000). An important feature of these papers is an emphasis on communication, in particular through the Internet that enables older people to communicate via e-mail with family and friends, to access information and to purchase goods. This emphasis is also consistent with literature sourced from overseas (Franklin 1997; Coulson 2000). The use of e-mail can also reduce social isolation for those older people with reduced mobility or living in remote or rural areas (Bishop 2000).

\section{Mental Health and the Social Environment}

Maintaining communication skills into old age is an important factor contributing to health and wellbeing (Worrall 1998). Communication skills can deteriorate with age due to reduced memory capacity, sensory deficits, and increasing word-finding difficulties. Shulman (Shulman 1988) suggests that as people grow older it is vital that their social networks and independence do not diminish in a society that revolves around more complex communication systems. Reduced communication skills in older people can result in social isolation. The Internet, particularly through its e-mail and chat technology, may help older people to avoid this isolation.

Social isolation can, potentially, be reduced through communication by accessing the Greypath Village chat rooms and also by leaving mail on the GreyPath Message Board. In the Village 3D virtual community visitors can chat anonymously at any time but particularly at popular times advertised by the Village Bulletin Board. Another way that the GreyPath portal may help older people to maintain social communication skills is by providing access to free on-line advisors who may not be available in a small local community either through physical access or via phone contact. For example, on the portal: 
- Tony Barber will answer questions on travel.

- Free advice is available on gardening.

- Medical advice is available for queries on disability issues.

- Enquiries can be made regarding the health of pets.

- Assistance is also provided on problems with computers or the Internet.

These can be significant services as small rural communities, in particular, may not have a local travel agent and it may be too expensive or inconvenient for these people to phone one in a larger town or city. Similar comments may also be applied to pet shops, computer stores and gardening centres.

\section{Physical Health and Well-being}

Byles et al. (1996) point out some other health concerns of older people include falls, inappropriate medication use, incontinence and nutritional deficiencies. These medical problems, he notes, can often be alleviated with appropriate health education programs, and the Internet may be an effective medium for the delivery of these programs.

By entering the GreyPath Village older people may easily find their way to the Village Interactive Health Centre where they can obtain one free health consultation from qualified medical personnel. Future consultations are charged for. Also there is a pharmaceutical link which enables older people to find information and to purchase both prescription and non-prescription medication. The Village Interactive Health Centre also has a chat facility where people can share and discuss health problems anonymously. For many older people, this is an important vehicle whereby concerns regarding health may be aired and others who have had similar problems in the past may share their experiences and course of treatment.

\section{Financial Security}

Older people in retirement feel a need to be assured of adequate income to maintain their lifestyle. Many older persons must arrange their own finances, and seek appropriate investment information relating to direct shares, managed funds and fixed interest investments including bonds and term deposits (Cutler 1997; Manchester 1997; Sherman 1997). The Internet could also be of assistance in providing information for this purpose.

The main page of the GreyPath portal has a 'Finance' information button, allowing visitors access to general finance advice from organisations such as National Seniors Association, Financial Planners Association of Australia, Comsec, Australian Pensioners Network, the Australian Tax Department and many others. There are also a number of Government programs including CentreLink and the National Information Centre on Retirement Investments.

\section{Intellectual Endeavours}

Many people are now working past the minimum retirement age (in Australia) of 55; indeed some older people are commencing new careers and having to learn a new set of skills (Baldi 1997). Others are taking up the challenge of further study, some even commencing degrees at university. Lifelong learning is seen to be a very positive aspect of a healthy ageing process (Bishop 2000), and while this is often delivered well by institutions such as the University of the Third Age (U3A) and the Centre for Adult Education (CAE), the Internet offers the possibility of providing a suitable vehicle for this purpose.

The GreyPath portal also has things that pertain to the 'mind'; catering for older people's intellectual needs. For example, the Village has a number of buildings with chat facilities where people can discuss matters of importance to themselves. The Lyceum building, a site for art enthusiasts, enables visitors to discuss their art interests anonymously. A single click allows the visitor entry to the Lyceum building where they can participate in an anonymous chat session. In addition to chatting, visitors to the Village Lyceum have the opportunity to enjoy a free art appreciation course, covering post 1945 Australian 
'icon' artists. 'Lookart', a virtual gallery, together with GreyPath, will be showcasing the works of a series of famous Australian artists over the next 12 months, focussing on a new artist every two weeks. One artist that has been reviewed is Howard Arkley, including information on his career development and exhibitions. Visitors are encouraged to return to the site via GreyPath with the promise of being able to explore the works of many other Australian artists such as Albert Tucker, John Perceval, Fred Williams, Joy Hester, Russell Drysdale, Arthur Boyd, Brett Whiteley, Jeffery Smart and Sidney Nolan. The Lookart virtual gallery provides links back to art gallery sites where some of the pieces displayed will be available for sale along with those advertised through Lookart.

\section{Special Needs of Older People in Rural Areas}

People living in regional areas and rural communities may not have the access to all the facilities that are available to those residing in metropolitan areas of Australia's large cities. For example, information needs and provision in rural areas can be different and some rural councils can offer only very limited transport for older and disabled people (Foskey 1998). Because of these problems, people living in regional and rural areas may find the Internet even more valuable than their counterparts in metropolitan Australia. The Internet is location independent and so ideal for use in these areas, providing the communications infrastructure is present.

Foskey (1998) speaks of the rhetoric in discussions of aged care that concerns enabling people to 'age in place' and points out how this is particularly significant in the case of rural communities where economic and emotional ties make moving an "unacceptable or unviable option" for many older people. She notes that in some cases they are 'locked' in place by not being able to afford to move because of declining rural property values.

\section{The GreyPath Portal}

The GreyPath portal concept was devised by Ray Lewis, a senior, who perceived a need for an Internet portal dedicated to other Australian seniors. As a consequence he developed and manages this portal (Lewis 2002). A Web portal can be seen as a special Internet (or intranet) site designed to act as a gateway to give access to all network-accessible resources whether involving intranets, extranets, or the Internet (Tatnall 2005). There are many different types of portal including: General Portals, Community Portals, Vertical Industry Portals, Horizontal Industry Portals, Enterprise Information Portals, e-Marketplace Portals, Personal/Mobile Portals, Information Portals and Niche Portals (Davison, Burgess and Tatnall 2004). The GreyPath portal can best be classified as a Community Portal.

Lewis (2002) describes GreyPath as "a uniquely styled, demographically 'inclusive', user-friendly, seniors web portal and virtual community that has been designed first and foremost to empower seniors and to enrich the quality of their lives." GreyPath aims to encourage site loyalty (Lepa and Tatnall 2002), identification with, and participation from its constituency, and in 2002 the portal received some 400,000 hits per month, constituting about 5000 to 6000 different visitors (Lewis 2002). Lewis indicates general benchmark figures for people consistently returning to Web sites are around 20-25\%, but that GreyPath is getting about 37\% return rate which suggests a very high loyalty factor. He points out that it is crucial to have people coming back as this means that with the new people you also attract, you are ever increasing your numbers.

GreyPath has three major components:

1. Firstly, there are links that are informational, or categories that pertain to the 'mind' (Lewis 2002). These include finance, legal, health, education, services, travel, art and culture, and entertainment.

2. The second group are more everyday needs type categories that Lewis describes as pertaining to the 'heart' such as relationships, news and the weather.

3. The third major component of the portal is the Village, an innovative virtual community where older people can chat and communicate with each other anonymously about common interests. 


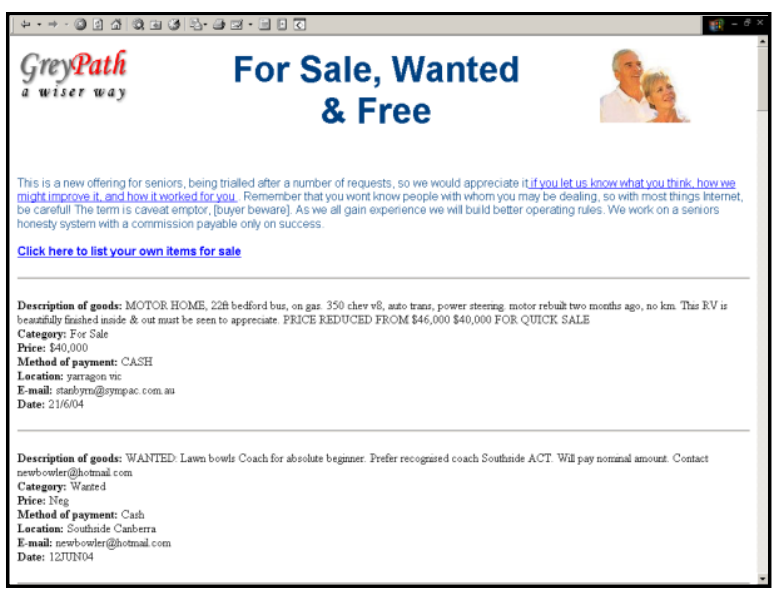
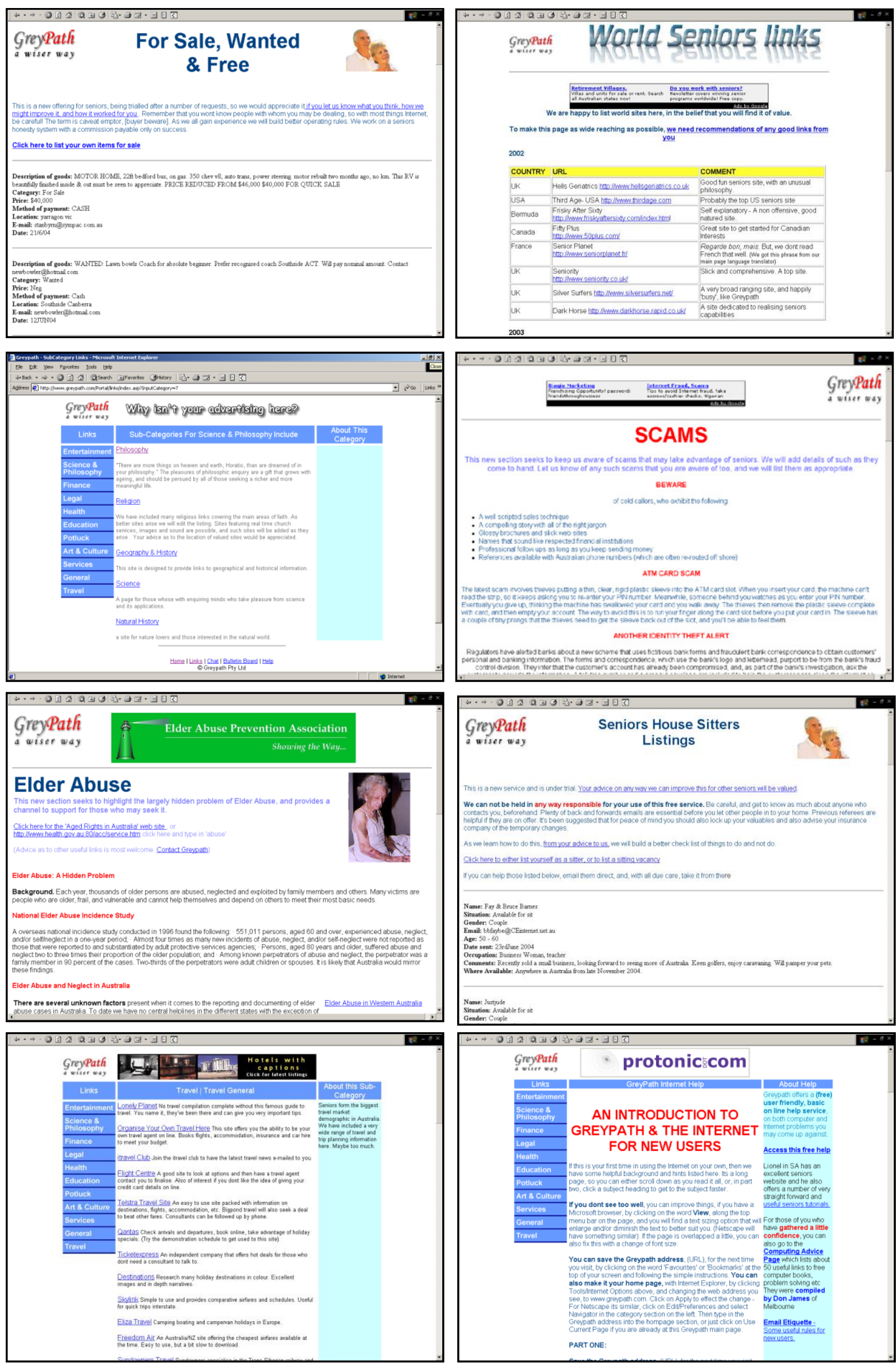

Figure 2: The GreyPath Portal - a variety of screens 
Lewis (2002) describes the GreyPath Village as a "world's first with a carefully specified and atmospherically crafted Virtual 3D community for seniors." The Village offers a variety of activities and a number of specialised chat rooms Lewis suggests that older people will find it more attractive to chat in the Village compared to many other more sophisticated sites spread across the world. He considers that advantages of the Village include simplicity (user friendliness), a naturalised visual environment, and clear potential for further development. The Village at GreyPath, through its Internet chat rooms, creates a virtual community of older people (Lepa and Tatnall 2002). The Village has eight chat rooms: Town Hall, Megs Café,

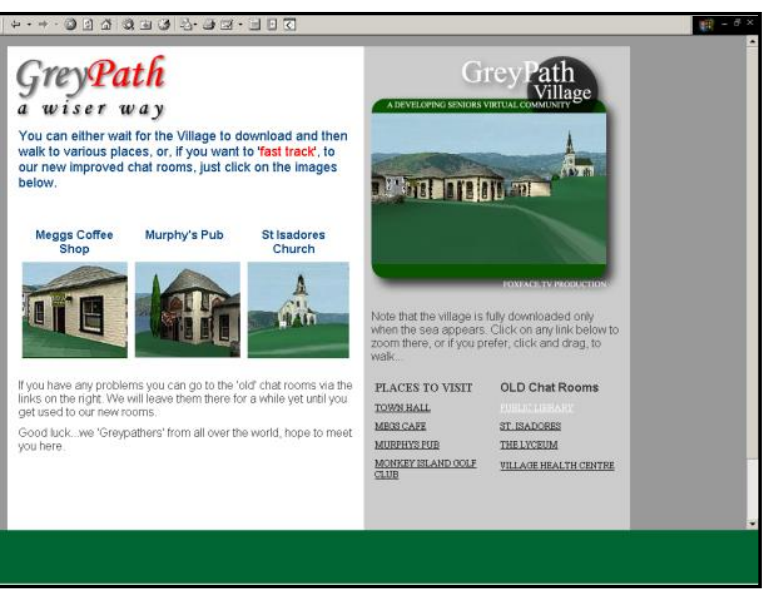

Figure 3: The GreyPath Village Murphy's Pub, the Public Library, St. Isadores, The Lyceum, Village Health Centre, and Monkey Island Golf Club. The idea is that these different chat rooms will allow people to speak easily about different topics with others who have similar interests. A major value of the Village is in strengthening the virtual community by encouraging frequent interactions by its members.

\section{Research Framework}

Many older people are quite innovative and entrepreneurial, and are prepared to consider the advantages offered by using the Internet. Conversely, others are happy to continue to do things in the same way they always have and see no need to investigate use of this technology. How and why people differ in this way, and why some adopt some technologies and not others should be considered using the framework of innovation theory. An innovation can be seen as "... an idea, practice, or object that is perceived as new by an individual ..." (Rogers 1995), and we will argue that the adoption of the Internet by an older person should be seen as an innovation and considered through the lens of innovation theory. The most widely accepted theory of how technological innovation takes place is provided by innovation diffusion (Rogers 1995), but most of the research based on this model involves studies of large organisations like General Electric, Xerox Park and the British Navy, or societal groups such as bottle-fed babies, adopters of mobile phones and organic farmers (Rogers 1995). This paper argues that another approach - that of innovation translation, has more to offer when considering details of the adoption of the Internet by older people.

The innovation translation approach draws on the sociology of translations, more commonly known as actor-network theory (ANT). In considering how the adoption of e-commerce by older people occurs it is necessary to examine their interactions with a number of other people. It is also important not to ignore the influence of the many non-human actors that are involved, including computers, modems, Web browsers, Internet service providers, e-mail documents and Web pages. In trying to understand this adoption it is useful to see these interactions in terms of negotiations, not just between humans but also involving non-humans.

Actor-network theory (Callon 1986; Law 1992; Latour 1996) attempts impartiality between all actors, whether human or non-human, and makes no distinction in approach between the social, the natural and the technological. Using an actor-network approach all the factors (both human and non-human) influencing e-commerce adoption are seen as actors, and the combination of all of these in terms of networks. It is a feature of actor-network theory that the extent of a network is determined by actors that are able to make their presence individually felt (Law 1987) by other actors. Grint and Woolgar (1997) note that an actor-network is configured by the enrolment of both human and non-human allies, and that this is done by means of a series of negotiations in a process of re-definition (Callon 1986) where one set of actors seeks to impose definitions and roles on others. In an innovation translation model the 
movement of an innovation is in the hands of people (Latour 1996) whom may react to it in different ways.

One reason often given by older people (Gross 1998; Bosler 2001) for adopting Internet technologies is, quite simply, so that the world does not pass them by and so that they won't be left out of things. The means of social interaction is increasingly moving away from posted letters to e-mail, and those not using e-mail are finding it harder to keep in touch. A growing number of older people are finding that an e-mail address has become essential (Perry 2000). Many older people consider that being able to keep in touch and to converse sensibly about technology with their grandchildren is very important (Alexander 2000). As this requires that they spend some time coming to grips with, and using the technology (Philbeck 1997) they make adoption decisions for this reason. In the same vein, being able to understand what is meant by a 'dot com', and why some people see the continuing growth of Microsoft as a threat, means that they need to engage with the technology (Perry 2000).

These, and related reasons for adoption of Internet technologies such as "All my friends use e-mail and I'll be left out if I don't" (Council on the Ageing 2000) suggest that characteristics of the technology have less to do with things than do social interactions and the creation and maintenance of interpersonal networks. We will illustrate this further in the brief case study examples that follow. Whereas innovation diffusion (Rogers 1995) places considerable importance on (supposedly) innate characteristics of the technology, innovation translation offers a research approach based on networks of human and non-human actors. For older people the issue of whether or not to adopt Internet technologies has been problematised (Callon 1986) in this context, not as one that relates to diverse characteristics of the technology, but as one specifically of communication and keeping in touch with family and friends. The growth of seniors' computer clubs is another example of this. The Internet, that is capable of so much, has been translated here to include just the means by which these people can maintain their place in society and keep relevant to their family and friends (Bosler 2001). What they have adopted is not the Internet as a business might know it, but a translation of the Internet resulting in technology that offers a means of maintaining contact with the world.

The three short accounts of Internet adoption by older people that follow result from research undertaken by the authors, and give some useful insights into how and why these people really adopt this technology. These accounts were derived from a series of interviews with older Internet users in 2001-2002. An important piece of methodological advice offered by the proponents of actor-network theory is to 'follow the actors' (Callon 1986; Latour 1996) and let them set the framework and limits of the study themselves. After initial discussions with the Focus Group, leaders in seniors computing clubs and other people involved in promoting the use of the Internet by older people, this process was followed to identify others to be interviewed. The accounts given below represent only a few of those obtained in this research.

Bernie (2001), a recently retired retail sales manager, has an interest in the stock market. He had, in the past, invested small sums through a firm of stockbrokers, and watched the fate of his shares with interest. The problem had been time, as he had been very busy at work. The lure of purchasing shares had always been, to him, more in the gamble than as a means of making money. Now that he had retired and had a lot more spare time, he had decided to indulge in this hobby in a bigger way. One day he read an article in the newspaper about using the Internet for share trading, and decided to give it a go. Knowing little of computers and the WWW he now needed to do some research into how to proceed. After purchasing the necessary hardware, setting up an account with an Internet Service Provider, and another with the on-line share broking service offered by his bank, he tried to make sense of using the Internet, and came to a full stop. It was all too hard. His motivation to succeed, however, was strong. He found out about a class offered by the local municipal library in use of the WWW, enrolled for the class, and overcame the block. Attending the class reinforced his early view that most of what was on the WWW was of little interest to him, but he did now know how to access any given site and could proceed with his on-line share trading. In terms of innovation translation he had problematised the Internet as a share broking service. If Bernie needed any more convincing, the fact that using the Internet was cheaper than his stockbroker, and that it removed the need to listen to the advice of the 
cocky young 'share expert', had provided it. This interessement quickly came between him and the stockbroker and led to his enrolment of the Internet as a means of share trading. Mobilisation occurred when he joined an investment club for retired people and began to convince the other members of the advantages of using the Internet.

Roy (2002), a retired history and geography teacher, has an interest in researching genealogy, and in the history of hand-tools used in woodwork, and has made use of the Internet for this purpose. With no background at all in the use of information technology he was initially most concerned that he would not be able to learn to use a computer, but a former colleague who lived nearby sat down with him and gave him some lessons in use of the WWW. He now makes occasional use of the Internet, by accessing computers at the local library, where he looks up information relating to his genealogical interests. He also accesses the Web sites of wood-working tool clubs around the world. With this translation the Internet became, to him, just a means of obtaining this information. Other aspects of the Internet were of little interest, and he would not have made the adoption based on what might be considered its innate characteristics (Rogers 1995). Roy could not accurately be said to have adopted the Internet as such at all, but rather a translation of it relating just to its use for obtaining information relating to genealogy and wood-working tools.

In a final example consider the case of Jean (2001), a Melbourne grandmother with family in London and Rome, considering the adoption of e-mail as a means of keeping in touch with them. Like many older people she had previously relied on posting airmail letters as she found the cost of phone calls too high. She also preferred writing to speaking on the phone. Electronic mail offered a problematisation of letter writing where the 'letters' could be short, informal, and sent as frequently as required for low cost, in contrast to the longer, more formal style of airmail letters. This offered her a translation of Internet use to become just a means of writing letters as often as she wanted, that will be 'delivered' very quickly and for low cost (once the computer system has been set up). Jean saw no point in 'browsing' or 'surfing the Internet' and would not have adopted Internet use for these reasons. This translation of the Internet to ignore all these features and concentrate just on letter writing is what was instrumental in convincing her to consider its adoption. All the other characteristics of the Internet were irrelevant to her (Bosler 2001). Without this translation she saw the Internet as too intimidating; now it was something she could understand and handle. Interessement was then offered by the informality, lower cost and quicker delivery time of the e-mail, in comparison to ordinary letters. This came between her and her use of ordinary mail and made e-mail seem even more attractive. The result was enrolment, as she saw and became convinced of the benefits of e-mail and then adopted this technology. She soon began to mobilise the technology by attempting to get other friends in Perth or New York to whom she currently also sent letters, to also adopt e-mail so that she could more easily communicate with them also.

As mentioned previously, this paper aims to illustrate the potential of a Web portal like GreyPath to fulfil some of the information and communication needs of older people, but not to set out research evidence to show that it is currently achieving this potential. This research forms a part of an ethnographic project, undertaken by the authors (Tatnall and Lepa 2001), to investigate how older Australians make use of Internet technologies, and how this use affects them in their daily lives. The authors assume that many or most of the visitors to GreyPath are older Australian people, but acknowledge that younger people may also find the site appealing and useful. Unfortunately this makes using the 'hit statistics' made available by those operating the site a little suspect.

\section{Further Research}

Further research could consider general issues such as: how do older people gain access to the Internet? Do they use it mainly from home, from local libraries, clubs or elsewhere? What induces them to use the Internet? What barriers make Internet use difficult? What do they gain from using the Internet? More specifically related to GreyPath, further research could determine which features of the portal older people find useful and worthwhile, and which they do not. It might also attempt to judge whether the portal is providing a service to older people that they see as valuable. Much of the literature discussing 
the needs of older people comes out of the USA, and some of this research is based upon such literature. Further work is needed to ascertain how the needs of older Australian people differ from those of North Americans. Further contact also needs to be made with researchers in the gerontology field, particularly regarding consideration of the effectiveness of the information included on the Web site, and how this is displayed to them.

\section{Conclusion}

In this paper we have outlined some of the needs of older people and proposed that use of Internet portals such as GreyPath offer a means of addressing these needs. In particular, because of their location-independence, Internet portals like GreyPath can be especially useful in providing services in rural areas. This technology has the potential to strengthen the bonds between older people living in a region that may be geographically far-flung, to make it into a vibrant virtual community (Tatnall and Lepa 2003). We have noted that while some older people find the idea of using the Internet threatening, others see it as a means of maintaining their independence. We have argued that in which of these groups older people find themselves has more to do with their network of interactions with both people and technology than with any innate characteristics of the technology itself.

Bernie was not interested in whether or not the Internet linked lots of sites around the world, or that it gave access to a wide range of interesting material; he only wanted to use it for share trading. Roy likewise only wanted to use the Internet to investigate genealogical information and sites relating to wood-working tools. That it provided access to much more information of other types was not the reason he adopted it. Jean's adoption of the Internet related only to her use of e-mail for communicating with her family and friends, not with browsing for information or amusement. In each case the adoption decisions of these people had little to do with any supposedly innate characteristics of the technology, but rather in specific uses of this technology that related to their social interactions and environment.

The theory of innovation diffusion concentrates largely on characteristics of the technology itself, while innovation translation looks at the formation of networks of human and non-human actors and how these networks interact. Translation looks more at the uses people might make of the innovation, and how the innovation needs to be translated for these uses to be achieved. It offers a means by which any number of small subtle factors can be addressed in each instance of adoption, rather than just looking for large-scale answers across the board. While diffusion theory may be useful in describing the worldwide movement to adopt Internet technologies, the cases described in this paper show that translation theory offers a better means of looking at the detail of individual adoptions. We contend that an innovation translation approach offers a useful way of investigating the detail of how and why older people adopt, or fail to adopt Internet technologies and electronic commerce. We argue that bringing out this detail is especially important in any understanding of how this complex process occurs, and that it allows useful insights that do not otherwise become apparent.

\section{References}

Alexander, M. (2000). Be Online or Be Left Behind - the Older Crowd Head for Cyberspace. Boston Globe. Boston.

Armstrong, A. and J., H. (2000). The Real Value of Online Communities. Knowledge and Communities. E. Lesser, Fontaine, M. A. and Lusher, J. A. Boston, Butterworth-Heinemann: 85-95.

AusIndustry (1996). Accessing export finance. South Melbourne, Vic, FT Pitman Publishing.

Australian Bureau of Statistics (2000). Use of the Internet by Householders. Canberra, Australian Government.

Baldi, R. A. (1997). "Training older adults to use the computer: Issues related to the workplace, attitudes, and training." Educational Gerontology 23(5): 453-466.

Barnatt, C. (1998). "Virtual communities and financial services - on-line business potentials and strategic choice." International Journal of Bank Marketing 16(4). 
Bergami, R. (2006). International trade: a practical introduction. Melbourne, Vic, Eruditions Publishing.

Bishop, A. P. (2000). "Communities for the New Century." Journal of Adolescent \& Adult Literacy 43(5): 472-479.

Bishop, B. M. (2000). Attitude, Lifestyle and Community Support Discussion Paper. Canberra, Australian Government Printing Service.

Bosler, N. (2001). Communication, E-Commerce and Older People. E-Commerce, Electronic Banking and Older People, Melbourne, Unpublished Seminar Presentation.

Byles, J. E., Garris, M. A., Nair, B. R. and Butler, J. R. G. (1996). "Preventive Health Programs for Older Australians." Health Promotion Journal of Australia 6(2): 37-43.

Callon, M. (1986). The Sociology of an Actor-Network: The Case of the Electric Vehicle. Mapping the Dynamics of Science and Technology. M. Callon, Law, J. and Rip, A. London, Macmillan Press: 19-34.

Callon, M. (1986). Some Elements of a Sociology of Translation: Domestication of the Scallops and the Fishermen of St Brieuc Bay. Power, Action \& Belief. A New Sociology of Knowledge? J. Law. London, Routledge \& Kegan Paul: 196-229.

Collins Publishers (1992). Collins English Dictionary. Australia, Harper Collins.

Coulson, I. (2000). "Introduction: Technological Challenges for Gerontologists in the $21^{\text {st }}$ Century." Educational Gerontology 26(4): 307-316.

Council on the Ageing (2000). Web Discrimination. ReportAge: 4.

Council on the Ageing (2000). Older People and the Internet Focus Group, Unpublished.

Cutler, N. E. (1997). "The False Alarm and Blaring Sirens of Financial Literacy: Middle Agers' Knowledge of Retirement." Generations 21(2): 34-41.

D'Arcy, L., Murray, C. and Cleave, B. (2000). Schmitthoff's Export Trade: The law and practice of international trade. London, U.K., Sweet and Maxwell.

Davison, A., Burgess, S. and Tatnall, A. (2004). Internet Technologies and Business. Melbourne, Data Publishing.

Documentary Credit World (2003). "Statistics: US Branches/Agencies of non-US banks." Documentary Credit World Available at: $<$ http://www.iiblp.org/pdf/dcw/DCW\%200ct\%202003.pdf $>$, Accessed 16-08-2004: 36 - 40.

Foskey, R. (1998). Changing families, challenging futures. $6^{\text {th }}$ Australian Institute of Family Studies Conference., Melbourne, Melbourne.

Franklin, M. B. (1997). Caught up in the 'Net': More and More Seniors are Discovering the Usefulness of Computers. The Washington Post. Washington: 17.

Grint, K. and Woolgar, S. (1997). The Machine at Work - Technology, Work and Organisation. Cambridge, Polity Press.

Gross, J. (1998). Wielding mouse and Modem, Elderly Remain in the Loop. The New York Times.

Hagel, J. and Armstrong, A. (1997). Net Gain: Expanding Markets through Virtual Communities. Harvard Business School. Boston, MA., Harvard.

Hamman, R. (2003). "Introduction to Virtual Communities Research." Cybersociology $y_{2}(2)$.

Henri, F. and Pudelko, B. (2003). "Understanding and analysing activity and learning in virtual communities." Journal of Computer Assisted Learning 19(4): 474-487.

ICC Australian Council (1992). Newsletter and work in progress, Number 3. Canberra, Australia, ICC Australia.

ICC Thailand (2002). Examination of documents waiver of discrepancies and notice under UCP500.

International Chamber of Commerce (1993). Uniform Customs and Practice for Documentary Credits. Paris, ICC Publishing, SA.

International Chamber of Commerce (1999). Incoterms 2000. Paris, France, ICC Publishing, S.A.

Jones, Q. (1997). "Virtual Communities, Virtual Settlements, and Cyberarchaeology: A Theoretical Outline." Journal of Computer-Mediated Communication 3(3).

Jones, S. (1995). Understanding Community in the Information Age. Cybersociety: Computer-mediated Communication and Community. G. Jones. Thousand Oaks, CA, Sage: 10-35. 
Kozinets, R. (1998). On netnography. Initial reflections on consumer research investigations of cyberculture. Advances in Consumer Research. J. Alba and Hutchinson, W. Provo, UT, Association for Consumer Research: 366-371.

Latour, B. (1996). Aramis or the Love of Technology. Cambridge, Ma, Harvard University Press.

Law, J. (1987). Technology and Heterogeneous Engineering: The Case of Portuguese Expansion. The Social Construction of Technological Systems: New Directions in the Sociology and History of Technology. W. E. Bijker, Hughes, T. P. and Pinch, T. J. Cambridge, Ma, MIT Press: 111-134.

Law, J. (1992). "Notes on the Theory of the Actor-Network: Ordering, Strategy and Heterogeneity." Systems Practice 5(4): 379-393.

Lepa, J. and Tatnall, A. (2002). Exploring Consumer Loyalty to Web Sites: Why Older Australians Return to the GreyPath Portal. We-B Conference, Perth.

Lepa, J. and Tatnall, A. (2002). The GreyPath Web Portal: Reaching out to Virtual Communities of Older People in Regional Areas. IT in Regional Areas (ITiRA-2002), Rockhampton, Australia, Central Queensland University.

Lepa, J. and Tatnall, A. (2002). Older People Adopting the GreyPath Village Lyceum: an Analysis Informed by Innovation Diffusion. AusWeb, Queensland.

Lepa, J. and Tatnall, A. (2004). Portal for Older People in Regional Areas: The GreyPath Virtual Community. Using Community Informatics to Transform Regions. S. Marshall, Taylor, W. and Xinghuo, Y. Hershey, PA, Idea Group Publishing: 209-222.

Lewis, R. (2002). Greypath Portal Interview. Melbourne.

Lloyd, S. (2001). Rise of the Cybersenior. Business Review Weekly.

Manchester, J. (1997). "Aging Boomers and Retirement: Who is at Risk?" Generations 21(2): 19-27.

Mann, R. J. (2000). "The role of letters of credit in payment transactions." Michigan Law Review 98(8): pp. 2494-2547.

Matathia, I. S. (1998). NEXT Trends for the Future. Australia, McMillan.

Mitchell, S. (2000). Catching the Silver Wave. The Australian. Melbourne: 53.

Muniz, A. M. (1997). Brand community and the negotiation of brand meaning. Advances in Consumer Research. M. Brucks and MacInnis, D. J. Provo, UT, Association for Consumer Research: 308309.

Perry, J. (2000). Retirees stay wired to kids - and to one another. U.S. News and World Report. USA: 22.

Philbeck, J. (1997). Seniors and the Internet. Cybersociology Magazine. http://members.aol.com/cybersoc/is2joyce.html.

Preece, J. (2000). Online Communities. New York, Wiley.

Ramberg, J. (1999). ICC Guide to Incoterms. Paris, France, ICC Publishing, S.A.

Rheingold, H. (1993). The Virtual Community: Homesteading on the Electronic Frontier. New York, Harper-Collins.

Rheingold, H. (1998). The Virtual Community: Homesteading on the Electronic Frontier.

Rogers, E. M. (1995). Diffusion of Innovations. New York, The Free Press.

Schneider, G. P. and Perry, J. T. (2001). Electronic Commerce. Boston, Course Technology.

Sherman, R. H. (1997). "Sources of Help in Financial Preparation for Retirement: AAAS to Web Sites." Generations 21(2): 55-61.

Shulman, L. S. (1988). Disciplines of Inquiry in Education: an overview. Complementary Methods for Research in Education. R. M. Jaeger. Washington, DC, American Educational Research Association.

SITPRO Ltd. (2003). Report on the use of export letters of credit 2001/2002. London, SITPRO Ltd.

Spry Foundation (2000). Older Adults and the World Wide Web. http://www.spry.org.

Swindell, R. (2002). "U3A Online: a virtual university of the third age for isolated older people." International Journal of Lifelong Education 21(5): 414-429.

Tatnall, A. and Lepa, J. (2001). Researching the Adoption of E-Commerce and the Internet by Older People. We-B Conference, Perth. 
Tatnall, A. and Lepa, J. (2003). "The Internet, E-Commerce and Older People: an Actor-Network Approach to Researching Reasons for Adoption and Use." Logistics Information Management 16(1): 56-63.

Tatnall, A. (2005). Portals, Portals Everywhere. Web Portals: the New Gateways to Internet Information and Services. A. Tatnall. Hershey, PA, Idea Group Publishing: 1-14.

Technical Officers of Global International Trade \& Business Finance (2000). Finance of International Trade. Melbourne, Australia, National Australia Bank.

United States International Trade Commission (2004). U.S. Trade by geographic regions, United States International Trade Commission. 2004.

Wenger, G. C. (1997). "Reflections: Success and Disappointment - Octogenarians Current and Retrospective Perceptions." Health Care in Later Life 2(4): 213-226.

Williamson, K., Bow, A. and Wale, K. (1996). "Barriers to Public Internet Access." Communications Research Forum: 36-50.

Worrall, L. L. (1998). “An evaluation of the Keep on Talking program.” Educational Gerontology 24(2.): 129-141. 